\title{
DESAIN DAN IMPLEMENTASI PENGUKUR KUALITAS UDARA PM10 BERBASIS MIKROKONTROLLER
}

\author{
Nur Arminarahmah ${ }^{1}$, Muhammad Rasyidan ${ }^{2}$, Zaenuddin ${ }^{3}$ \\ ${ }^{1,2,3)}$ Fakultas Teknologi Informasi, UNISKA MAB Banjarmasin \\ Email : $\underline{\text { nur.armina@fti.uniska-bjm.ac.id }}$,
}

\begin{abstract}
ABSTRAK
Kondisi udara pada lingkungan tempat tinggal sudah mulai tercemar oleh polutan-polutan berupa asap pembakaran lahan, asap rokok, asap kendaraan bermotor serta banyak lagi sumber polutan yang lain.Untuk proses pendeteksian kualitas udara pada lingkungan kampus UNISKA Banjarbaru maka dirancanglah sebuah alat yang berfungsi untuk mendeteksi kualitas udara berbasis mikrokontroller.Sensor yang digunakan adalah DSM501a sebagai sensor pengukur kadar polutan PM10 dan MQ-135 sebagai sensor tambahan untuk jenis polutan seperti amonia, $\mathrm{CO}_{2}$, Asap dan gas.Mikrokontroller yang digunakan adalah Arduino Uno.
\end{abstract}

Kata kunci : Arduino Uno,DSM501a ,PM10,

\begin{abstract}
Air conditions in the environment where the living has begun polluted by pollutants such as land-burning smoke, cigarette smoke, motor vehicle fumes and many other sources of pollutant. We designed a Microcontroller based tool that serves to detect Air quality campus environment of UNISKA Banjarbaru.Sensor used is DSM501a as a sensor measuring levels of pollutants PM10,CO2, Smoke. The used is Arduino Uno.
\end{abstract}

Keyword :Arduino UNO,DSM501a, PM10

\section{PENDAHULUAN}

Udara merupakan komponen penting dalam kehidupan manusia dan makhluk hidup lainnya sehingga perlu dipelihara kualitasnya agar dapat berfungsi maksimal untuk mendukung kehidupan yang sehat bagi makhluk hidup.

Polutan memiliki dampak terhadap kesehatan dan lingkungan ([1] ). Dampak kesehatannya berupa infeksi saluran pernapasan [1], [2], ([10], [11], [15] selain berdampak pada pernapasan juga berbahaya bagi kesehatan jantung [1], [2], dan mengganggu pertumbuhan tulang pada anak-anak [3].Terhadap lingkungan mengganggu jarak pandang dalam [9], [13], [14], [15], dan kenyamanan berada diluar ruangan.

Kondisi lingkungan yang padat penduduk tidak terlepas dari asap baik dari hasil pembakaran hutan, asap rokok dan pembakaran dari kendaraan bermotor.Peringatan secara tertulis tidak berdampak maksimal untuk mengurangi tingkat polusi khususnya larangan merokok dan peringatan terhadap alat transportasi yang mengeluarkan asap-asap kendaraan bermotor serta tingkat pembakaran lahan, sehingga perlu suatu rancang bangun yang diharapkan mampu digunakan sebagai pendeteksi tingkat kualitas udara serta sebagai peringatan berupa alarm ketika terdeteksi asap baik PM10, asap rokok atau jenis polusi udara lainnya di wilayah kampus UNISKA Banjarbaru.

\section{TINJAUAN PUSTAKA}

Polutan adalah benda yang menyebabkan pencemaran sesuatu terutama air atau atmosfer [4].Untuk polutan udara berupa partikel (partikulate mater), oksidan fotokimia dan ozon tingkat bumi, karbon monoksida, sulfur oksida ,nitrogen oksida dan timbal.

Klasifikasi polutan dapat dibagi menjadi dua bagian, yaitu :

1. Polutan Primer, yaitu polutan yang dikeluarkan langsung dari sumber tertentu dan dapat berupa gas $(\mathrm{CO}, \mathrm{CO} 2, \mathrm{~S}, \mathrm{~N}, \mathrm{Cl}, \mathrm{F}, \mathrm{NO} 2, \mathrm{SO} 2)$

2. Polutan Kimiawi yaitu polutan yang berbentuk senyawa kimia baik senyawa sintetis maupun alami ( S04, Logam, Timbal dan merkuri ) 
3. Polutan Biologis yaitu polutan yang berbentuk makhluk hidup yang dapat menimbulkan pencemaran ( Bakteri E.Coli, Gulma )

Emisi adalah jumlah polutan yang di keluarkan ke udara dalam suatu satuan waktu tertentu. Emisi dapat disebabkan oleh proses alam misalnya asap kendaraan bermotor, asap pabrik dan sisa pembakaran. [5]

\section{II.1 PARTICUlATE MATER 10 (PM10)}

Particulate mater atau polusi partikel merupakan campuran partikel padat dan tetesan cairan yang ditemukan di udara.Beberapa partikel seperti debu, kotoran, jelaga atau asap yang sangat pekat dapat terlihat jelas oleh mata sedangkan partikel yang begitu kecil hanya dapat dideteksi dengan menggunakan mikroskop elektron. [4]

Asap merupakan campuran bahan partikulat,uap, gas dan abu secara garis besar Particulate Mater dibagi menjadi 3 kelompok yaitu: PM10, PM2,5, dan PM1 $1 \mu \mathrm{m}$ [6].PM10 merupakan jenis partikel yang bisa dihirup oleh hidung dengan diameter berukuran 10 mikrometer.PM 2,5 partikel dengan diameter 2,5 mikrometer dan PM1 diameter parikelnya 1 mikrometer. [6].

Sumber dari polutan PM10 adalah bisa dari lokasi konstruksi, jalan beraspal, pembakaran lahan serta asap kendaraan bermotor [4].

\section{II.2 DAMPAK KESEHATAN}

Dampak polutan PM10 terhadap kesehatan yaitu saat partikel masuk ke sistem pernafasan menyebabkan gangguan pada infeksi saluran pernapasan ([10]; [1]; [2]; [15]; [11] dan PM10 juga berdampak bagi kesehatan jantung [1], [2], serta mengganggu pertumbuhan tulang pada anak-anak [3].Disamping dampak terhadap kesehatan dampak yang ditimbulkan oleh PM10 juga pada lingkungan, cuaca dan iklim ([12]; [16]; yang serta kerusakan properti.

Ukuran median diameter PM10 yaitu kurang dari $10 \mu \mathrm{m}$ dan bisa lolos dari saringan [14]buat hidung [7] sehingga menyebabkan jenis polutan ini masuk ke sistem pernafasan sehingga menyebabkan gangguan infeksi saluran pernapasan serta polutan ini juga berbahaya bagi kesehatan jantung ([10]; [1]; [2]; [15]; [11].Dampak yang paling besar adalah pengaruh pada jarak pandang karena mengganggu jalur cahaya melalui efek penyerapan dan pemencaran [9].

\section{II.3 MIKROKONTROLLER}

Mikrokontroller (pengendali mikro) merupakan rangkaian elektronik yang memiliki fungsi mengendalikan serta mengatur cara kerja pada rangkaian elektronika.

Perbedaan utama dari mikrokontroller dan mikroprosesor adalah mikrokontroller tidak hanya memiliki CPU juga dilengkapi dengan memori, input dan output sebagai perlengkapan minimum dari sebuah mikrokomputer yang dapat berdiri sendiri sedangkan mikroprosessor merupakan sebuah central processing unit (CPU) elektronik komputer yang terbuat dari transistor mini serta memiliki sirkuit lainnya di atas sebuah sirkuit terintegrasi yang bersifat semikonduktor tapi tanpa ada interface untuk input dan output.

Mikrokotnroller Arduino Uno adalah papan elektronik yang komponen utamanya adalah chip mikrokontroller dengan jenis AVR dan bersifat open source [8].Mikrokontroller memiliki banyak tipe dan saah satu mikrokontroller yang akan digunakan pada penelitian ini adalah Arduino Uno.

Sensor yang digunakan adalah DSM501a yaitu sensor yang berfungsi sebagai pengukur kadar PM10.

\section{III.HASIL PEMBAHASAN}

\section{III.1 PERANCANGAN DESAIN DAN IMPLEMENTASI}

Prinsip kerja dari desain dan implementasi ini adalah saat alat mikrokontroller terdeteksi asap yang jumlah kepekatan diluar dari normal maka akan ada pemberitahuan pada layar lcd berupa skala kepekatan asap sebagai peringatan kadar polutan diruangan kampus uniska banjarbaru. 
Deteksi polutan berdasarkan hasil deteksi sensor asap dan PM10 yaitu menggunakan sensor DSM501a .Sensor asap ini bekerja berdasarkan perubahan tegangan sesuai dengan jumlah gumpalan yang diterima permukaan sensor, sehingga jika nilai gumpalan asap yang terbaca mencapai nilai yang telah ditentukan untuk kondisi abnormal maka sistem sensor memberikan informasi pada layar led berupa angka kepekatan adanya polusi udara pada ruangan.

\section{III.2 PERSIAPAN HARDWARE}

Persiapan hardware untuk mendeteksi adanya polusi udara pada ruangan, maka diperlukan sensor asap. Sensor asap yang digunakan pada rancang bangun ini menggunakan DSM501a serta datasheet, flame sensor DSM501a mampu menangkap asap dengan rata-rata $940 \mathrm{~nm}$ dengan lebar bandwidth spectrum panjang gelombang 760nm - 1100nm sehingga sangat cocok digunakan untuk mendeteksi adanya sumber asap didekat permukaan sensor, sementara itu output dari modul sensor asap DSM501a berupa tegangan yang mempresentasikan besar kecilnya kondisi asap yang diterima permukaan sensor sehingga pada perancangan ini output dari sensor dihubungkan dengan pin analog (ADC) pada ARDUINO.

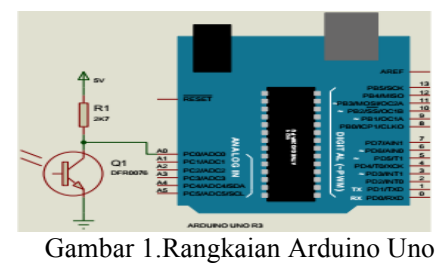

\section{III.3 Perancangan Perangkat Lunak}

Perangkat Lunak pada perancangan alat ini dibangun menggunakan bahasa $C$ dengan compiler Codevision AVR. Keseluruhan maupun perangkat lunak untuk mengakses bagian-bagian dari sistem diatur didalam Arduino UNO Atmega328.

\section{III.3.1 ALGORITMA PEMBACAAN ADC INTERNAL ARDUINO}

Algoritma pengkonversian data analog ke digital melalui ADC Internal Arduino Uno meliputi beberapa pa[14]eter dan register yang disetting dan ditunjukkan pada perancangan flowchart

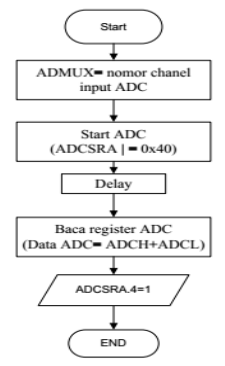

Gambar 2.Flowchart Proses ADC Internal Arduino UNO

Pengertian Delay disini adalah waktu tunda dari internal control ADC pada mikrokontroller yang dimanfaatkan untuk proses konversi. Proses tersebut diatur berdasarkan konfigurasi ADC dari clock yang dirancang, sementara itu untuk mengetahui proses selesainya konversi ADC berada pada register ADCSRA pada bit ke 4, yaitu bit akan 0 saat konversi ADC selesai dan berlogika 1 (high) jika proses konversi sedang berlangsung.Hasil konversi ADC selanjutnya disimpan pada register ADCH untuk bit MSB ( bit 8 dan bit 9) sementara bit rendah (LSB) tersimpan pada register ADCL yaitu bit 0 hingga 7 sehingga data dapat diambil dari register tersebut,selanjutnya bit ADCSRA bit ke 4 di buat high secara manual sebagai tanda pada internal controller ADC bahwa data ADC telah dibaca.

Pada pemrog[14]an arduino, sistem pembacaan ADC melalui perangkat lunak arduino telah dikemas menjadi satu perintah sederhana yaitu analog.read(analog input) sehingga seting pa[14]eter pada register ADC sebagaimana gambar telah dilakukan secara otomatis pada Arduino UNO. 


\section{III.3.2 ALGORITMA PEMBACAAN SENSOR PM10 DSM501a}

Sensor DSM501a adalah jenis sensor gas yang berfungsi untuk mengetahui konsentrasi gas karbon monoksida dan sensor ini salah satunya dipakai dalam memantau gas karbonmonoksida.

Karakter dari sensor DSM501a ini memiliki tingkat sensitivitas tinggi dan waktu respon yang cepat.Keluaran yang dihasilkan oleh sensor ini adalah berupa sinyal analog.Sensor ini juga membutuhkan tegangan sebesar 5V serta sensor ini memiliki nilai resistansi sensor yang dapat berubah jika terkena gas dan sebagai pembersihan ruangan sensor dari kontaminasi udara luar. Keluaran sensor ini dihubungkan dengan analog digital converter,sehingga keluaran dapat ditampilkan dalam bentuk sinyal digital. Rangkaian sensor diberi tenaga tegangan sebesar $5 \mathrm{~V}$ dan diberi komponen resistor sebagai beban agar tidak terkena arus yang terlalu besar.

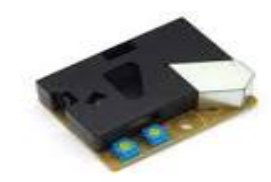

Gambar 3.Sensor DSM501a

\section{PENGUJIAN}

Saat alat pertama kali dinyalakan maka LCD akan menampilkan inisialisasi penangkapan sinyal, dan yang terakhir LCD akan menampilkan kadar asap dan status kondisi kepekatan asap dari api. Tampilan awal LCD digambarkan pada Gambar dibawah ini,sedangkan untuk proses inisialisasi penangkapan sinyal serta status tetap LCD.

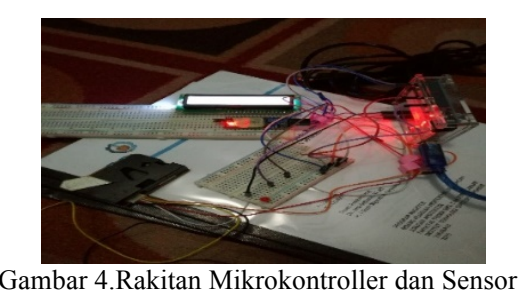

Source code dibawah ini merupakan sorce code yang digunakan untuk menampilkan data ke lcd

void loop() \{

duration $=$ pulseIn $($ pin, $L O W)$;

lowpulseoccupancy $=$ lowpulseoccupancy + duration;

lcd.setCursor $(0,1)$

lcd.print(ratio);

lcd.setCursor $(9,1)$;

lcd.print(concentration);

Proses pengujian adanya asap yaitu dengan cara memberikan asap rokok serta pembakaran kertas pada sensor DSM501a. Pada kondisi awal saat inisialisasi pada arduino saat catu daya telah aktif dan software keseluruhan sudah didownload pada rangkaian.

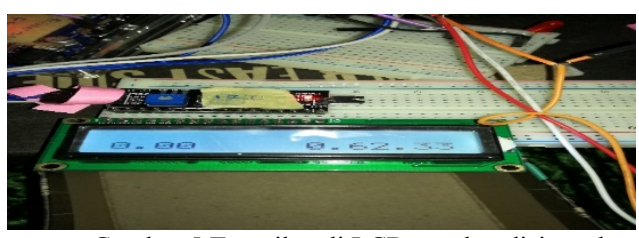

Gambar 5.Tampilan di LCD saat kondisi awal 


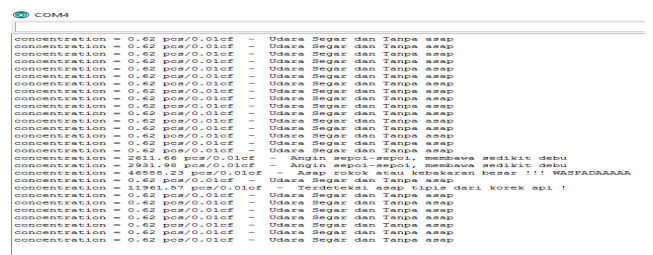

Gambar 6.Hasil Data Sensor dari kondisi tanpa asap

Rangkaian penghisap gas pada bagian atas sensor DSM501a yang berguna untuk mengambil sampel gas yang akan diuji dan saklar elektronik yang berfungsi untuk memicu deteksi asap.Rangkaian penghisap gas ini akan bekerja dalam rentang waktu.Penghitungan kadar partikulat matter pada kandungan gas haruslah diketahui volume gas yang akan diuji. Untuk mengetahui volume gas yang terhisap diperlukan rumus: $V=$ A.w.r.t , dengan $V=$ volume gas, $A=$ luas penampang, $\omega=$ kecepatan putar penghisap, $r=$ jari-jari penampang, dan $t=$ waktu.Pengujian rangkaian Penimbang dilakukan untuk mengetahui tegangan yang dikeluarkan oleh rangkaian penimbang pada sensor PM10.

Source code untuk proses perhitungan kadar asap didalam alat sensor asap yang kemudian diupload ke mikrokontroller untuk diproses

ratio $=$ lowpulseoccupancy/(sampletime_ms $* 10.0) ; / /$ Integer percentage $0=>100$

concentration $=1.1 *$ pow $($ ratio, 3$)-3.8 *$ pow $($ ratio, 2$)+520 *$ ratio $+0.62 ; / /$ using spec sheet curve

if (concentration < 1.0) \{Serial.println("Udara Segar dan Tanpa asap "); \}

if (concentration $>1.0 \& \&$ concentration < 10000) \{Serial.println("Angin sepoi-sepoi, membawa sedikit debu");

if (concentration $>10000 \& \&$ concentration < 15000) \{Serial.println("Terdeteksi asap tipis dari korek api !");

if (concentration > 15000) \{Serial.println("Asap rokok atau kebakaran besar !!! WASPADAAAAA ");

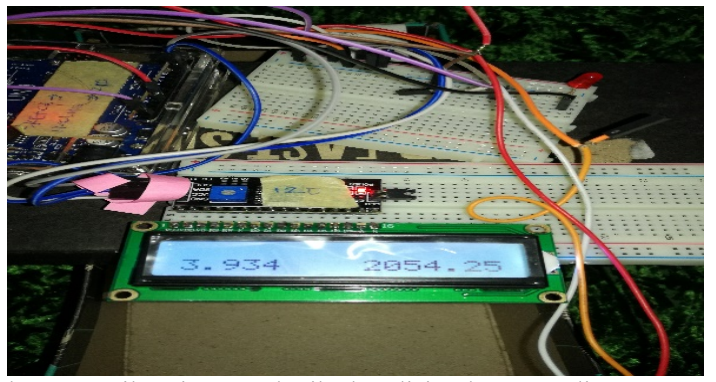

Gambar 7. Hasil peringatan ketika kondisi polutannya diatas rata-rata

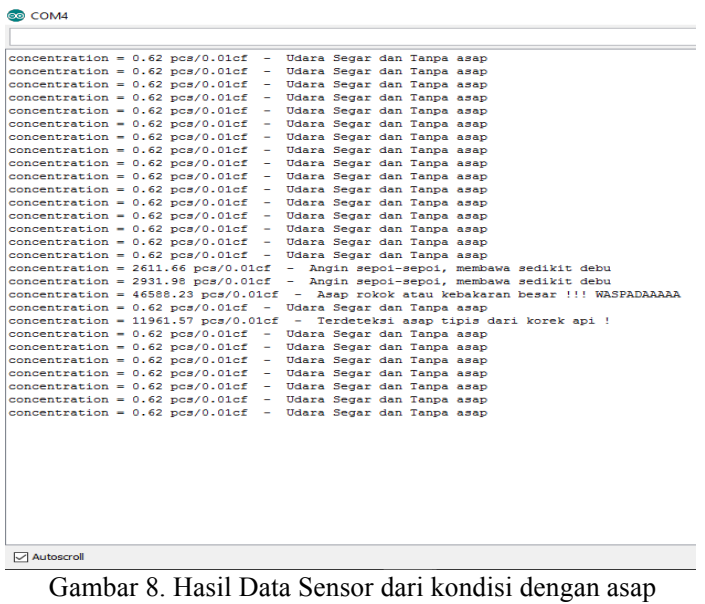




\section{IV.KESIMPULAN DAN SARAN}

Berdasarkan hasil perancangan dan analisa sistem yang dirancang, maka kesimpulan dari desain dan implementasi mikrokontroller yaitu dapat diuraikan sebagai berikut:

1. Hasil pengujian perangkat sensor pada lingkungan didalam ruangan secara langsung dapat terdeteksi dengan menggunakan perangkat sensor yang digunakan dan siap digunakan dalam sistem pengendalian dapat dikembangkan untuk kondisi yang luas cakupannya.

2. Pengembangan visualisasi informasi melalui website atau media yang lebih informatif sehingga dapat berfungsi maksimal sebagai sistem pengawasan kualitas udara dan sebagai saran untuk pengembangan lebih luas yang dipadukan dengan visualisasi data yang baik dapat meningkatkan penyampaian informasi kepada masyarakat khususnya pada masyarakat sekitar lingkungan kampus UNISKA Banjarbaru.

3. Sensor asap rokok yang dirancang menggunakan DSM501A bertugas mendeteksi asap dengan perubahan terhadap kepekatan asap kemudian dikonversi menjadi tegangan agar dapat dibaca ADC.

4. Pengembangan yang diharapkan adalah dapat dikombinasikan kedalam beberapa sensor lain sehingga rancang bangun dapat berfungsi lebih baik dan informasi yang dihasilkan juga lebih variatif dan bermanfaat tidak hanya untuk mengukur kwalitas udara.

\section{DAFTAR PUSTAKA}

[1] World Health Organization, "Public health, environmental and social determinants of health (PHE)," [Online]. Available: http://www.who.int/phe/air_quality_q\&a. [Accessed 104 2016].

[2] Huboyo [2] dan Sutrisno, "Analisis Konsentrasi Particulate Matter 10 (PM10) pada Udara Diluar Ruang (Studi Kasus : Stasiun Ta[13] - Semarang)," TEKNIK, vol. 30, no. 1, pp. 44-48, 2009.

[3] C.Liu [3], E. Fuertes, C. Flexeder, L. C. Hofbauer, D. Berdel, B. Hoffmann, J. Kratzsch, A. v. berg and J. Heinrich, "Associations betweens Ambient Air Pollution and Bone Turnover Markers in 10-year old children: Result from the GINIplus and LISAplus Studies," International Journal of Hygiene and Environmental Health, vol. 218, pp. 58-65, 2015.

[4] Oxford Dictioneries, "pollutant - definition of pollutant in English from the Oxford dictionary," 8 September 2013. [Online]. Available: http://www.oxforddictionaries.com/us/definition/american_english/pollutant.

[5] Kistinnah I ; Lestari ES, Biologi Makhluk Hidup dan Lingkungannya, Jakarta: Pusat Perbukuan departemen Pendidikan Nasional, 2006.

[6] P. G. Satsangi, A. Kulshrestha, A. Taneja and P. S. Rao, "Measurements of PM10 and PM2. 5 in aerosols in Agra, a semi-arid region of India," Indian Journal of Radio \& Space Physics, vol. 40, pp. 203-210, 82011.

[7] A. Gindo and B. Hari, "Pengukuran Partikel Udara Ambien (Tsp, PM10, PM2, 5) Di Sekitar Calon Lokasi Pltn Semanjung Lemahabang," in Prosiding seminar nasional teknologi pengolahan limbah VI, 2012.

[8] Efendi Ilham, "Pengertian dan Kelebihan Arduino," 2014. [Online]. Available: http://www.it-jurnal.com.

[9] Sabetghadam, Samaneh, and Farhang Ahmadi Givi. 2014. "Relationship of Extinction Coefficient, Air Pollution, and Meteorological Parameters in an Urban Area during 2007 to 2009." Environmental Science and Pollution Research 21 (1): 538-47. doi:10.1007/s11356-013-1901-9.

[10] Bunawas Tjasyono, Klimatologi Umum, Bandung: ITB, 1999.

[11] Yusnabeti, Ririn Arminsih Wulandari, and Ruth Luciana. 2010. "PM10 Dan Infeksi Saluran Pernapasan Akut Pada Pekerja Industri Mebel.” Makara Kesehatan 14 (1): 25-29.

[12] Bhaskar dan M Mehta. 2010. "Atmospheric Particulate Pollutants and Their Relationship with Meteorology in Ahmedabad.” Aerosol and Air Quality Research 10 (4): 301-15. doi:10.4209/aaqr.2009.10.0069.

Wang, Jun, Zimei Hu, Yuanyuan Chen, Zhenlou Chen, and Shiyuan Xu. 2013. "Contamination Characteristics

[13] and Possible Sources of PM10 and PM2.5 in Different Functional Areas of Shanghai, China." Atmospheric Environment 68 (3663). Elsevier: 221-29. doi:10.1016/j.atmosenv.2012.10.070.

Ram, Kirpa, M. M. Sarin, and S. N. Tripathi. 2012. “Temporal Trends in Atmospheric PM2 . 5 , PM10 , 
[14] Elemental Carbon, Organic Carbon, WaterSoluble Organic Carbon, and Optical Properties: Impact of Biomass Burning Emissions in The Indo- Gangetic Plain.” Environmental Science \& Technology 46 (2): 686-95.

Abdullah, Nur Aleesha, Siti Hawa Shuhaimi, Toh Ying Ying, and Afizal Haqeem Shapee. 2011. "The Study of

[15] Seasonal Variation of PM10 Concentration in Peninsular, Sabah and Sarawak." Malaysian Meteorological Department 9: 1-28.

Choi, Yong Sang, Chang Hoi Ho, Jinwon Kim, Dao Yi Gong, and Rokjin J. Park. 2008. "The Impact of Aerosols on the Summer Rainfall Frequency in China.” Journal of Applied Meteorology and Climatology 47 [16] (6): 1802-13. doi:10.1175/2007JAMC1745.1

[17] Zhang, Kuang-ling. 2002. "Spatial and Seasonal Variation of PM10 Mass Concentrations in Taiwan." Atmospheric Environment 36 (21): 3403-11. 